The following table shows the constant $(\mathrm{O}-\mathrm{C})$ and the accidental errors attached to different observers' measures. The errors are inversely proportional to the aperture of the object glass. It appears from Asaph Hall's observations that the errors in the observed angle increase as the distance decreases owing to the increased difficulty of seeing the companion.

\begin{tabular}{|c|c|c|c|c|c|c|}
\hline Observer & $P$ & $n$ & Angle & $\begin{array}{l}\text { P.E. } \\
\text { arc. }\end{array}$ & $\begin{array}{l}\text { Dista } \\
\text { Const. }\end{array}$ & $\begin{array}{l}\text { nce } \\
\text { P.E. }\end{array}$ \\
\hline Bond & 10.0 & 4 & $\pm 0: 80$ & \pm 0.14 & +0.48 & ? \\
\hline Winlock & I I.I & 3 & \pm 0.85 & \pm 0.17 & +0.01 & \pm 0.21 \\
\hline Peirce & 11.2 & 4 & \pm 1.81 & \pm 0.35 & -0.15 & \pm 0.05 \\
\hline Lassell \& Marth & I 0.0 & 4 & \pm 0.44 & \pm 0.08 & -0.07 & $?$ \\
\hline O. S & 10.4 & 5 & \pm 1.27 & \pm 0.23 & +0.29 & \pm 0.16 \\
\hline Engelmann & 10.0 & 4 & 土I.I 4 & \pm 0.20 & 一 & - \\
\hline Vogel & I I.I & 3 & $\pm 2.3^{8}$ & \pm 0.46 & +0.37 & \pm 0.30 \\
\hline Newcomb & I I.I & 4 & $\pm 0.6_{5}$ & \pm 0.13 & +0.08 & \pm 0.09 \\
\hline Holden & 10.8 & 8 & $\pm \mathbf{1 . 2 3}$ & \pm 0.23 & +0.43 & \pm 0.28 \\
\hline Pritc & 10.3 & 5 & \pm 0.84 & \pm 0.15 & +0.13 & \pm 0.15 \\
\hline Stone & 10.3 & 5 & \pm 1.35 & \pm 0.24 & -0.05 & \pm 0.10 \\
\hline Wilson & 8.6 & 5 & \pm 1.26 & \pm 0.19 & -0.23 & \pm 0.27 \\
\hline Hall & 9.9 & I I & \pm 0.89 & \pm 0.15 & -0.07 & \pm 0.13 \\
\hline , & 7.9 & 7 & \pm 1.44 & \pm 0.20 & +0.02 & \pm 0.12 \\
\hline Hol & 8.7 & 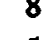 & \pm 0.58 & \pm 0.09 & -0.19 & \pm 0.11 \\
\hline Bigo & $9 \cdot 5$ & 5 & \pm 0.68 & $\pm 0.1 \mathrm{I}$ & +0.01 & \pm 0.14 \\
\hline Dun & I I.3 & 5 & \pm 1.14 & \pm 0.22 & -0.36 & \pm 0.22 \\
\hline
\end{tabular}

Hongkong Observatory, 1904 June 24.

$\begin{array}{lllcc}\quad \text { Observer } & \rho & n & \begin{array}{c}\text { Angle P.E. } \\ \text { arc. }\end{array} & \begin{array}{c}\text { Distance } \\ \text { Const. P.E. }\end{array} \\ \text { Burnham } & 8.7 & 9 & \pm 0.59 \pm 0.09 & -0.15 \pm 0.07 \\ \text { Young } & 8.4 & 6 & \pm 0.64 \pm 0.09 & +0.10 \pm 0.12 \\ \text { See } & 4.1 & 3 & \pm 3.67 \pm 0.26 & +0.45 \pm 0.38 \\ \text { Aitken } & 4.2 & 8 & \pm 1.58 \pm 0.12 & +0.06 \pm 0.06 \\ \text { Hussey } & 4.8 & 9 & \pm 0.38 \pm 0.03 & -0.04 \pm 0.06 \\ \text { Barnard } & 5.5 & 5 & \pm 2.30 \pm 0.22 & +0.09 \pm 0.11\end{array}$

The following ephemeris shows the apparent places.

\begin{tabular}{|c|c|c|c|c|}
\hline Epoch & $\Delta a$ & $\Delta \delta$ & $\theta$ & $\rho$ \\
\hline 1903.2 & +0.368 & -2.94 & $119: 0$ & 6.05 \\
\hline 1904.2 & $+0.4 \times 8$ & -2.54 & I 12.9 & 6.52 \\
\hline 1905.2 & +0.464 & -2.12 & 107.6 & 6.99 \\
\hline 1906.2 & +0.505 & -1.67 & 103.0 & $7 \cdot 45$ \\
\hline 1907.2 & +0.543 & -1.22 & 98.8 & \\
\hline 1908.2 & +0.576 & -0.75 & 95.2 & 8.31 \\
\hline 1909.2 & +0.606 & -0.28 & 91.9 & 8.72 \\
\hline 1910.2 & +0.632 & +0.19 & 88.9 & 9.09 \\
\hline 1911.2 & +0.655 & +0.66 & 86.0 & 9.44 \\
\hline 1912.2 & +0.675 & +1.03 & 83.4 & 9.77 \\
\hline $19 \div 3.2$. & +0.691 & +1.59 & 81.0 & 10.06 \\
\hline I 9 I 4.2 & +0.704 & +2.04 & 78.6 & 10.33 \\
\hline 1915.2 & $+0.7 \times 5$ & $+2.4^{8}$ & 76.4 & 10.57 \\
\hline 1916.2 & +0.722 & +2.92 & 74.3 & 10.78 \\
\hline $19 \times 7.2$ & +0.726 & +3.34 & 72.3 & 10.95 \\
\hline
\end{tabular}

W. Doberck.

\title{
A system of time-keeping \\ specially adapted to a locality where earthquakes are frequent.
}

\section{By $K$. Sotome.}

Japan is a well-known land for earthquakes. We, the inhabitants, are constantly threatened by their irresistible destructive power. Fortunately, however, the majority of them are comparatively small oscillations (with long periods and short amplitudes), detectible only by sensitive seismographs. Those which can be felt by our bodies are a small fraction of the total number. These macroseismic vibrations are of larger amplitudes and shorter periods (usually less than one second). After all, it is comparatively seldom that wé suffer from damages to bour property, but there is a matter of importance with respect to which we are almost fatally obstructed by seismic disturbances.

In the present state of our knowledge, the pendulumclock is the most efficient instrument as a time-keeper, provided the ground beneath it is quite steady. When disturbed by a seismic movement, the problem of the pendulum motion becomes almost insuperably complicated. This is the reason why chronometers are adopted at present as the principal time-keepers in our land. However, the accuracy of these delicate instruments is far from satisfactory to us in spite of the utmost care with which we treat them. It seems to be too troublesome for the chronometer to be accepted as an astronomical time-keeper. Thus we find ourselves in a dilemma when we seek to promote the degree of accuracy of the present time-keeping system. For the last few years $I$ have interested myself in trying to make some improvements in this all-important matter. At last $I$ have come to devise a system that makes a conjoint use of a pendulumclock and a chronometer. I here propose this system as the best adapted to districts visited by earthquakes.

First of all $I$ take it as granted a priori that the pendulum-clock is the best time-keeper, so long as the ground is steady, and also that the chronometer is quite inserdsible to earthquakes. Then, if we can measure the quantity of disturbance which the pendulum-clock suffers from an earthquake, we can extend the use of the clock to the whole time. This is my fundamental idea for solving the present problem. To actualize the proposition thus hypothetically stated, I combine a clock and a chronometer with a chronograph, by means of which we can obtain a precise comparison of the two time-keepers. If we are making ceaseless comparisons of them, we are naturally able to detect any change of their relative rate. Therefore, so long as we can assume that the chronometer is insensible to earthquakes, we are able to measure the disturbance incurred by the clock through a certain seismic movement. It is convenient to make the comparisons by an automatic method; so I joined an electro-magnet to the chronograph, 
the coil of which was connected with an ordinary clock. This secondary clock is so constructed that an electric circuit is automatically made through it regularly once an hour for about twenty seconds. When the circuit is made, the electro-magnet acts upon the chronograph in such a way that the chronograph is set going and at the same time electric circuits are completed through two time-keepers. In this way we obtain their successive comparisons from hour to hour; so that the investigation of their relative hourly rates becomes quite easy. We are thus enabled to make inspections of the behaviour of the chronometer rate throughout the day, and ultimately find its short-period inequalities, if any such exist, as for instance, the diurnal periodicity due to the effect of winding and also that due to the diurnal change of temperature. With respect to the inequalities of the chronometers I shall take a later opportunity of further discussion.

When an earthquake is detected by the seismograph, we at once refer to the chronometer, and from the preliminary investigations we can determine its hourly rate and readily calculate the quantity of disturbance suffered by the clock-pendulum. This is the correction to be applied to the clock face time, besides that due to its ordinary rate.
An earthquake may possibly cause a change in the amplitude of the pendulum. We can detect this by watching the subsequent hourly comparisons after the occurrence of the disturbance. In this case we have to wait a few hours for the return to the normal state.

I shall now proceed to a brief description of my experience hitherto gathered, which has continued from the end of the year I901, although interrupted on a few occasions, owing to hindrances in the instruments and some other causes. The clocks Dent Nos. I 588 and 1958, both installed in a vault, kept in a constant temperature, have been used alternately for the purpose. Several chronometers all kept in the transit room, have also been put at my service in turn. I need give no details about my chronograph, except that it is a modified form of Morse's, combined with some auxiliary apparatus as already described. As we have not yet been provided with a seismograph to take a record of earthquakes, I have been obliged to make use of the data taken from the instrument of the Central Meteorological Observatory, which is situated some two miles away from us.

I shall now take some typical examples to illustrate the mode of finding the change of clock face time due to the disturbances of earthquakes.

Example I. On Jan. I, 1902, the relative hourly rate of Dent $195^{8}$ (clock) and Dent 3078 (chronometer) runs as follows:

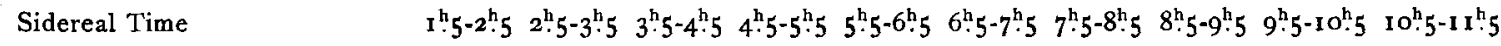

$\begin{array}{lllllllllll}\text { Relative rate, clock faster } & 0.56 & 0.58 & 0.57 & 0.55 & 0.57 & 0.56 & 0.56 & 0.55 & 0.54 & 0.56\end{array}$

At $7^{\mathrm{h}} 16^{\mathrm{m}} 54^{\mathrm{s}}$, there was a seismic tremor, but we could not trace its effect on the relative rate. So $\mathrm{I}$ concluded that this earthquake had no perceptible disturbing effect on the clock-pendulum.

ran as follows:

Example II. The relative rate of Dent 1958 (clock) and Negus I844 (chronometer) on March 31, 1902, Sidereal Time

$\begin{array}{llllllllll}\text { Relative rate, clock faster } & 0.02 & 0.03 & 0.03 & 0.03 & 0.03 & 0.00 & 0.02 & 0.03 & 0.03\end{array}$

An earthquake occurred at $18^{\mathrm{h}} 24^{\mathrm{m}} 34^{\mathrm{s}}$. I assign the above change of relative rate in the corresponding interval to this disturbance and infer that the clock was retarded by the amount o...03. as follows:

Example III. The relative rate of Dent $195^{8}$ (clock) and Negus 1622 (chronometer) on June 24, J902, ran

Sidereal Time $\quad 8^{\mathrm{h}} \cdot 5-9^{\mathrm{h}} \cdot 5 \quad 9^{\mathrm{h}} \cdot 5-10^{\mathrm{h}} \cdot 5 \quad 10^{\mathrm{h}} \cdot 5-11^{\mathrm{h}} \cdot 5 \quad 11^{\mathrm{h}} \cdot 5-12^{\mathrm{h}} \cdot 5 \quad 12^{\mathrm{h}} \cdot 5-13^{\mathrm{h}} \cdot 5 \quad 13^{\mathrm{h}} \cdot 5-14^{\mathrm{h}} \cdot 5 \quad 14^{\mathrm{h}} \cdot 5-15^{\mathrm{h}} \cdot 5 \quad 15^{\mathrm{h}} \cdot 5-16^{\mathrm{h}} \cdot 5 \quad 16^{\mathrm{h}} \cdot 5-17^{\mathrm{h}} \cdot 5 \quad 17^{\mathrm{h}} \cdot 5-18^{\mathrm{h}} \cdot 5 \quad 18^{\mathrm{h}} \cdot 5-19^{\mathrm{h}} \cdot 5 \quad 19^{\mathrm{h}} \cdot 5-20^{\mathrm{h}} \cdot 5$

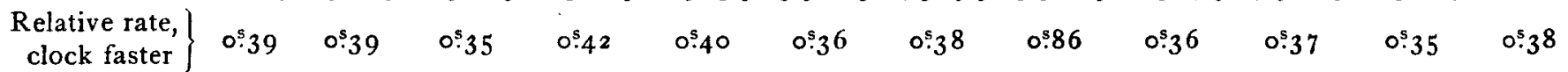

An earthquake took place at $15^{\mathrm{h}} 33^{\mathrm{m}} 30^{\mathrm{s}}$. From the above series we can conclude that the pendulum clock was accelerated some 0.48 .

Example IV. The result of observation of the relative rate of Dent $5_{5} 88$ (clock) and Frodsham $355^{8}$ (chronometer) on June 22,1903 , was known to be as follows:

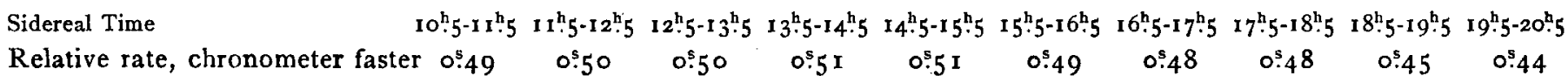

In spite of the fact that there was an earthquake beginning at $16^{\mathrm{h}} 50^{\mathrm{m}} 45^{\mathrm{s}}$, we cannot find its effect in the above series of relative rate. So I come to the conclusion that the disturbance of that time had no sensible effect on the pendulum motion of the clock.

I will conclude this paper for the present by exhibiting the result so far obtained in the following columns, in which column I gives the date, column 2 the Tokyo sidereal time at the beginning of the earthquake, column 3 the

character of the earthquake, and column 4 gives the effect of the earthquake on the clock face time; "acc. \& means the second hand was accelerated and ,ret. \& retarded. 


\begin{tabular}{|c|c|c|c|c|c|c|c|c|c|c|}
\hline \multicolumn{3}{|c|}{ Date } & \multicolumn{3}{|c|}{ Sid. Time } & \multirow{3}{*}{$\frac{\text { Earthquake }}{\text { Tremor }}$} & \multirow{2}{*}{$\frac{\text { Effect }}{0}$} & Clock & Chronometer & Remark \\
\hline I 901 & Nov. & 23 & I $9^{\mathrm{h}}$ & ${ }^{b} 8^{m}$ & ${ }^{\mathrm{m}} \mathrm{I} 4^{\mathrm{s}}$ & & & Dent $195^{8}$ & Kittel $\mathbf{I}_{\mathbf{3}}$ & - \\
\hline & » & 26 & I & $I_{4}$ & 15 & & 0 & $>$ & * & - \\
\hline & » & 26 & I 5 & 50 & 5 & 》 & $\circ$ & > & » & - \\
\hline & » & 27 & 23 & 34 & 30 & » & acc. 0.05 & » & » & - \\
\hline & Dec. & 6 & 4 & 24 & $3^{2}$ & » & ret. 0.05 & $»$ & • & - \\
\hline & $»$ & r 4 & 5 & 55 & I 4 & $\gg$ & $?$ & 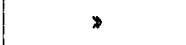 & $\gg$ & 1) \\
\hline & $"$ & 16 & 7 & $3 I$ & 42 & $\begin{array}{c}\text { Weak, but } \\
\text { sudden, \& long }\end{array}$ & $?$ & , & » & 1) \\
\hline & $»$ & 31 & 7 & 19 & 2 I & Tremor & 0 & 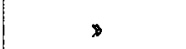 & Dent 3078 & - \\
\hline 1902 & Jan. & I & 7 & 16 & 54 & » & 0 & 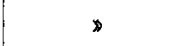 &, & - \\
\hline & 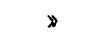 & I 3 & r 6 & 50 & $4 \mathrm{I}$ & » & 0 & » & $\rtimes$ & - \\
\hline & 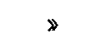 & I 6 & I 2 & I 8 & 23 & » & o & $\bowtie$ & $»$ & - \\
\hline & $»$ & I 7 & I 2 & 44 & 18 & $\gg$ & 0 & , & Negus 1844 & - \\
\hline & » & 25 & 20 & 0 & 2 & $\gg$ & 0 & » & $\rightarrow$ & - \\
\hline & 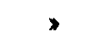 & 29 & 8 & 15 & 43 & » & $\circ$ & » & $\cdot$ & - \\
\hline & $»$ & 30 & 7 & $5^{6}$ & 2 I & Tremor, long & acc. 0.13 & $\triangleright$. & $\gg$ & - \\
\hline & , & 30 & 19 & 39 & 46 & Tremor & acc. 0.05 & 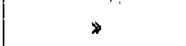 & » & - \\
\hline & Mar. & 2 & 23 & 48 & 46 & $\nu$ & 0 & $\gg$ & $»$ & - \\
\hline & » & 2 & 20 & 10 & $5^{6}$ & $»$ & acc. 0.07 & , & $»$ & - \\
\hline & $»$ & 30 & 20 & 46 & 3 & , & 0 & 》 & $»$ & - \\
\hline & $\star$ & $3 \mathbf{I}$ & I 8 & 24 & 34 & $\gg$ & ret. 0.03 & » & , & - \\
\hline & May & $\mathrm{I}_{7}$ & 5 & I 2 & 39 & 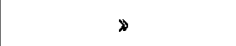 & ret. 0.02 & ๖ & Kittel $\mathbf{I}^{\mathbf{2}}$ & - \\
\hline & $»$ & 28 & ro & 44 & I I & 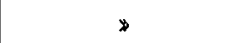 & acc. 0.03 & 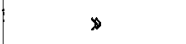 & Negus 1844 & - \\
\hline & June & I 2 & 22 & 22 & I I & » & 0 & $»$ & Negus 1622 & - \\
\hline & 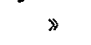 & 12 & $\mathbf{z}$ & 46 & $3^{8}$ & » & 0 & » &, & - \\
\hline & * & 24 & 15 & 33 & 30 & $»$ & acc. $0.4^{8}$ & , & » & - \\
\hline & $»$ & 26 & 7 & 43 & 57 & , & 0 & ঃ & » & - \\
\hline & * & 26 & 14 & 0 & 5 & $\$$ & 0 & $\gg$ & » & - \\
\hline & 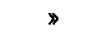 & 27 & I 4 & 53 & $3^{1}$ & » & $\circ$ & $\gg$ & 》 & - \\
\hline 1903 & Mar. & 7 & 18 & 32 & 6 & » & $\circ$ & Dent I 588 & Frodsham $355^{8}$ & - \\
\hline & $»$ & 8 & I 8 & 46 & 17 & $»$ & ret. 0.03 & $\gg$ & ( & - \\
\hline & » & I 3 & $\circ$ & 48 & 29 & $»$ & acc. 0.08 & > & Negus 1844 & - \\
\hline & \$. & I3 & 2 & 42 & 24 & » & $\circ$ & > & » & - \\
\hline & April & $\mathbf{I}$ & 12 & 4 & 0 & $»$ & o & » & Negus 1678 & - \\
\hline & 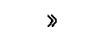 & I 5 & $\mathbf{I}$ & 42 & 27 & $\gg$ & $\circ$ & » & $*$ & - \\
\hline & $>$ & 16 & 3 & 45 & 3 & $》$ & ret. 0.03 & , & $»$ & - \\
\hline & $》$ & 19 & 9 & $5^{2}$ & $4^{8}$ & 》 & 0 & $\gg$ & Negus 1627 & - \\
\hline & $»$ & 20 & 23 & $2 \mathrm{I}$ & 36 & » & acc. 0.02 & > & $\gg$ & - \\
\hline & June & 22 & I 6 & 50 & 45 & ע & 0 & > & Frodsham $355^{8}$ & - \\
\hline & 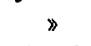 & 26 & 6 & 44 & I 9 & » & $\circ$ & , & Negus 1844 & - \\
\hline 1904 & April & 2 & 7 & 2 I & 57 & » & $\circ$ & Dent $195^{8}$ & $\$$ & - \\
\hline & : & 9 & I 4 & 37 & I I & $\gg$ & $\circ$ & $\gg$ & » & - \\
\hline & 》 & 23 & I9 & $x_{2}$ & 38 & $\begin{array}{l}\text { Tremor, slow, } \\
\text { duration } 3^{\mathrm{m}} 50^{\mathrm{s}}\end{array}$ & acc. $I .5^{\circ}$ & $»$ & * & - \\
\hline & May & I I & 23 & $5^{2}$ & 3 & Tremor & ret. $\quad 0.03$ & 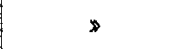 & $\gg$ & - \\
\hline & $\gg$ & 17 & 4 & 48 & 43 & $»$ & 0 & » & Negus 1678 & - \\
\hline & $»$ & 17 & 7 & 59 & 42 & Tremor, slow & $\circ$ & » & , & - \\
\hline & 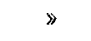 & I 8 & 4 & I 7 & 28 & 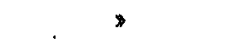 & o & 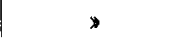 & * & - \\
\hline
\end{tabular}

Remark: r) Chronometer rate was not regular enough.

Tokyo Astronomical Observatory, 1904 July 23.

$K$. Sotome.

Berichtigung.

In dem seitens der v. Kuffnerschen Sternwarte versandten Zirkular, Über neue Refraktionstafelne ist auf Seite 3 Zeile 2 v. $0.760^{\mathrm{mm}} \mathrm{zu}$ streichen und Zeile 2 v. u. statt $\log \Delta$ zu lesen $\log \rho$. 